\title{
Cobaias como modelo para teste de vacinas inativadas contra o herpesvírus bovino tipo 1 e o vírus da diarréia viral bovina
}

\author{
Guinea pigs as a model test of bovine herpesvirus type 1 and bovine viral diarrhea virus \\ inactivated vaccines
}

\author{
Letícia Frizzo da Silva' ${ }^{\mathrm{I}}$ Diego Gustavo Diel ${ }^{\mathrm{I}}$ Maria do Carmo Cilento ${ }^{\mathrm{II}}$ \\ Rudi Weiblen ${ }^{\mathrm{III}}$ Eduardo Furtado Flores ${ }^{\mathrm{III}^{*}}$
}

\section{RESUMO}

O presente trabalho relata a avaliação de cobaias como modelo para testes de imunogenicidade de vacinas inativadas contra o herpesvírus bovino tipo 1 (BoHV-1) e o vírus da diarréia viral bovina $(B V D V)$. Para isso, cobaias $(n=60)$ e bovinos $(n=10)$ foram imunizados duas vezes, com intervalo de 28 dias, com uma vacina experimental contendo antígenos dos dois vírus, e testados para anticorpos neutralizantes 28 dias após a segunda dose. Os bovinos foram vacinados com a dose recomendada para a espécie $(5 \mathrm{~mL})$; as cobaias foram distribuídas em seis grupos e imunizadas com doses fracionadas $(0,005 \mathrm{~mL}$ a 1,6mL). Os grupos de cobaias imunizadas com doses equivalentes a 1/16 (0,320mL) e 1/8 (0,640mL) da dose bovina desenvolveram títulos médios geométricos (GMTs) de 6,46 e 7,56, respectivamente, estatisticamente semelhantes aos dos bovinos $(G M T=8)(P>0,05)$. Uma alta correlação doseresposta $\left(R^{2}=0,95\right)$ foi observada entre as doses vacinais e os títulos de anticorpos neutralizantes anti-BoHV-1 nos grupos de cobaias. Por outro lado, não foi possível o estabelecimento de uma dose vacinal que induzisse em cobaias uma resposta neutralizante anti-BVDV em níveis semelhantes à induzida em bovinos. Apenas as cobaias imunizadas com as doses maiores $(0,640$ e 1,6mL) desenvolveram títulos neutralizantes de magnitude moderada (GMTs de 8 e 9, respectivamente), porém estatisticamente inferiores ao GMT dos bovinos $(G M T=34,9)$ $(P<0,05)$. Esses resultados demonstram que cobaias podem ser utilizadas como modelo para estudos da imunogenicidade de vacinas inativadas contra o BoHV-1. Volumes entre 1/8 e 1/ 16 da dose bovina são suficientes para induzir nesta espécie uma resposta neutralizante de magnitude equivalente à de bovinos.

Palavras-chave: $B o H V-1, \quad B V D V$, cobaias, modelo experimental, teste de vacinas.

\begin{abstract}
The present study reports the use of guinea pigs as a model to study the immunogenicity of bovine herpesvirus type 1 (BoHV-1) and bovine viral diarrhea virus (BVDV) inactivated vaccines. To this purpose, guinea pigs (60) and calves (10) were immunized twice with a 28 day interval with an experimental vaccine containing antigens of both viruses and tested for virus neutralizing (VN) antibodies 28 days after the second dose. Calves were immunized with the recommended dose $(5 \mathrm{~mL})$, while the guinea pigs were distributed in six groups and immunized with fractionated doses (0.005 to $1.6 \mathrm{~mL})$. Guinea pigs immunized with $1 / 16(0.320 \mathrm{~mL})$ and $1 / 8$ $(0.640 \mathrm{~mL})$ of the bovine dose developed VN titers (GMTs) of 6.46 and 7.56, respectively, which were equivalent to the titers developed by calves $(G M T=8)(P>0.05)$. A high correlation $\left(R^{2}=0.95\right)$ was observed between the antigen dose and the $V N$ titer developed by all guinea pig groups. On the other hand, it was not possible to establish an antigen dose that induces in guinea pigs a serological response to BVDV equivalent to that induced in calves. Only the two groups given the highest antigen doses developed a consistent anti - BVDV neutralizing response, yet with $V N$ titers (GMT $=8$ and 9, respectively) significantly lower $(P<0.05)$ than that induced in calves $(G M T=34.9)$. These results demonstrate that guinea pigs may be used as a model to test the immunogenicity of BoHV-1 inactivated vaccines. Volumes between 1/8 and 1/16 of the bovine dose induce in these animals a VN antibody response of equivalent magnitude to that induced in calves.
\end{abstract}

Key words: BoHV-1, BVDV, experimental model, guinea pigs, vaccine test.

'Programa de Pós-graduação em Medicina Veterinária, Universidade Federal de Santa Maria (UFSM), Santa Maria, RS, Brasil.

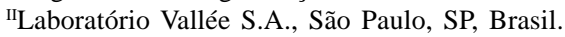

IIIDepartamento de Medicina Veterinária Preventiva (DMVP), Centro de Ciências Rurais (CCR), UFSM, Santa Maria, RS, Brasil. Fone/fax: 55-32208034. E-mail: flores@ccr.ufsm.br. *Autor para correspondência. 


\section{INTRODUÇÃO}

O herpesvírus bovino tipo 1 (BoHV-1) e o vírus da diarréia viral bovina (BVDV) são importantes patógenos de bovinos e possuem distribuição mundial (BAKER, 1995; TIKOO et al., 1995). A afecção clínica mais comum da infecção pelo BoHV-1 é a rinotraqueíte infecciosa bovina (IBR). Esse agente também está associado com enfermidade no trato genital (balanopostite e vulvovaginite), conjuntivite e infecção sistêmica, além de abortos (TIKOO et al., 1995). Após infecção aguda, o BoHV-1 estabelece infecção latente, sendo a reativação desta última, um importante mecanismo de manutenção e disseminação do vírus na natureza (JONES, 1998).

O BVDV também está associado com uma ampla variedade de afecções, que variam desde infecções subclínicas até enfermidade aguda fatal. A infecção pode resultar em enfermidade respiratória ou digestiva (diarréia viral bovina, BVD), doença das mucosas (DM) ou trombocitopenia acompanhada de diarréia aguda e hemorrágica fatal (BAKER, 1995). A infecção de fêmeas prenhes freqüentemente resulta em transmissão transplacentária do vírus para o feto, podendo ocasionar mortalidade embrionária ou fetal, abortos, mumificações, malformações, nascimento de bezerros fracos e inviáveis, além do nascimento de animais persistentemente infectados (PI) (BAKER, 1995).

A vacinação tem sido freqüentemente utilizada para reduzir as perdas associadas com as infecções pelo BoHV-1 e pelo BVDV, e uma variedade de vacinas inativadas e com vírus vivo modificado (MLV) têm sido utilizadas contra esses agentes (VAN OIRSCHOT et al., 1999; VAN DRUNEN LITTEL-VAN DEN HURK, 2005). No entanto, apesar da diversidade de imunógenos disponíveis, ainda não existe uma vacina totalmente efetiva para o controle dessas enfermidades.

No Brasil, várias vacinas nacionais e importadas contendo antígenos inativados do BoHV-1 e do BVDV estão atualmente em uso (FLORES et al., 2005). Não obstante, vários laboratórios nacionais estão desenvolvendo novas vacinas, sobretudo devido à restrição da importação de imunobiológicos de alguns países, e também pela necessidade de serem incluídos isolados locais nas vacinas (FLORES et al., 2005). A avaliação da imunogenicidade de formulações vacinais requer necessariamente o uso de animais, de preferência os da espécie hospedeira natural. No entanto, o uso de bovinos nesses testes é dificultado pelo alto custo e pela dificuldade de obterrem-se propriedades soronegativas, devido à ampla circulação desses agentes no rebanho brasileiro (LOVATO et al., 1995; FLORES et al., 2005). Nesse sentido, o estabelecimento de um modelo experimental em animais de laboratório pode tornar-se uma ferramenta útil para a pesquisa e o desenvolvimento de novas vacinas contra o BoHV-1 e oBVDV.

O presente trabalho teve como objetivo gerar parâmetros sorológicos em cobaias comparáveis aos induzidos em bovinos imunizados com antígenos do BoHV-1 e do BVDV, procurando avaliar essa espécie como modelo e estabelecer doses antigênicas equivalentes para cobaias e bovinos.

\section{MATERIAL E MÉTODOS}

Bezerros e cobaias foram imunizados duas vezes com intervalo de 28 dias com uma formulação vacinal contendo antígenos inativados do BoHV-1 e BVDV. Os bovinos foram imunizados com a dose recomendada para a espécie, enquanto as cobaias foram distribuídas em seis grupos e imunizadas com doses fracionadas. A resposta sorológica à vacinação foi avaliada por testes de soroneutralização (SN), com o soro colhido 28 dias após a revacinação.

Grupos experimentais, vacina e protocolo de vacinação

Bovinos: dez bezerros com idades entre 10 e 14 meses e peso médio de $220 \mathrm{~kg}$, soronegativos para o BoHV-1 e o BVDV, foram imunizados pela via subcutânea com uma formulação experimental inativada, contendo antígenos totais do BoHV-1 e BVDV em veículo aquoso e sais de alumínio como adjuvante. Os animais foram vacinados de acordo com as recomendações do fabricante, duas doses de $5 \mathrm{~mL}$ com intervalo de 28 dias. Dois bovinos permaneceram como controles, sendo não vacinados.

Cobaias: 65 cobaias da raça Hartley, com peso aproximado de $500 \mathrm{~g}$, foram distribuídas aleatoriamente em seis grupos compostos de 10 animais cada. Cada grupo foi imunizado com uma dose fracionada do mesmo imunógeno utilizado nos bovinos (Tabela 1). A formulação vacinal, a via de admnistração e a freqüência das imunizações foram as mesmas utilizadas para os bovinos. Cinco cobaios permaneceram como controle, não semdo vacinados.

\section{Células e vírus}

Os procedimentos de multiplicação dos vírus e os testes de soroneutralização (SN) foram realizados em células MDBK (Madin-Darby bovine kidney; American Type Culture Collection (ATCC), 
Tabela 1 - Resposta sorológica de bovinos e cobaias imunizados com uma vacina inativada contra o herpesvírus bovino tipo 1 (BoHV-1) e o vírus da diarréia viral bovina (BVDV) 28 dias após a revacinação.

\begin{tabular}{|c|c|c|c|c|c|c|c|}
\hline \multirow[b]{2}{*}{ Grupo } & \multirow[b]{2}{*}{$\begin{array}{l}\text { Dose } \\
(\mathrm{mL})\end{array}$} & \multicolumn{3}{|c|}{ BoHV-1 } & \multicolumn{3}{|c|}{ BVDV } \\
\hline & & Reagentes $^{\mathrm{a}}$ & Títulos individuais ${ }^{\mathrm{b}}$ & $\mathrm{GMT}^{\mathrm{c}}$ & Reagentes & Títulos individuais & GMT \\
\hline Bovinos & 5 & $10 / 10$ & $2,4,8(5), 16(3)$ & $8^{e}$ & $8 / 10$ & $<2(2), 8,16(3), 64,128(3)$ & $38^{\mathrm{e}}$ \\
\hline Cobaias 1 & 0,005 & $0 / 10$ & $<2^{\mathrm{d}}(10)$ & $<2^{f}$ & & $<2(10)$ & $<2$ \\
\hline 2 & 0,02 & $0 / 10$ & $<2(10)$ & $<2^{\mathrm{f}}$ & $2 / 10$ & $<2(8), 2,4$ & $2,82^{f}$ \\
\hline 3 & 0,08 & $5 / 10$ & $<2(5), 2(5)$ & $2^{f}$ & $2 / 10$ & $<2(8), 2,4$ & $2,82^{f}$ \\
\hline 4 & 0,320 & $7 / 8$ & $<2,2,4$ (3), 8 (2), 64 & $6,56^{\mathrm{e}}$ & $2 / 8$ & $<2(6), 2(2)$ & $2^{f}$ \\
\hline 5 & 0,640 & $10 / 10$ & $2(2), 4,8(4), 16(2), 32$ & $7,46^{\mathrm{e}}$ & $7 / 10$ & $<2$ (3), 4 (2), 8 (4), 32 & $8^{\mathrm{g}}$ \\
\hline 6 & 1,6 & $9 / 9$ & $16(2), 32(4), 64,128(2)$ & $40,31^{\mathrm{g}}$ & $7 / 9$ & $<2$ (3), 2 (2), 8 (2), 32, 64 & $9^{g}$ \\
\hline
\end{tabular}

${ }^{\mathrm{a}}$ Número de animais que reagiram sorologicamente à vacinação/total de vacinados.

b Títulos desenvolvidos pelos bovinos e cobaias do grupo (número de reagentes com o mesmo título).

c Título médio geométrico.

d Anticorpos neutralizantes não-detectados na menor diluição de soro testada: 1:2 para ambos BoHV-1 e BVDV.

${ }^{\text {eg }}$ Valores de GMT com letras iguais não diferiram entre si frente ao BoHV-1 ou ao BVDV.

CCL-22) livres de pestivírus. As células foram cultivadas em meio essencial mínimo (MEM) acrescido de 10.000UI $\mathrm{L}^{-1}$ de penicilina, 200mg L ${ }^{-1}$ de estreptomicina, 25mg L $\mathrm{L}^{-1}$ de fungizona e soro eqüino (10\%). As cepas padrão Cooper (BoHV-1) e Singer (BVDV-1) utilizadas para os testes de SN foram gentilmente cedidas pelo Dr. Fernando Osório e pelo Dr. Ruben Donis (Department of Veterinary and Biomedical Sciences, University of Nebraska at Lincoln, Lincoln, USA).

\section{Sorologia}

Amostras de soro coletadas no dia da segunda dose e 28 dias após (dia 56) foram testadas para a presença de anticorpos neutralizantes contra o BoHV-1 e o BVDV pela técnica de soroneutralização (SN), de acordo com VOGEL et al. (2002). Os testes de SN foram realizados utilizando-se diluições crescentes de soro, partindo de 1:2 até 1:256, frente a doses constantes dos vírus (100 TCID T0 $_{50}$ - doses infectantes para 50\% das células/cavidade) e células MDBK como indicador. Os títulos de anticorpos neutralizantes foram expressos como a recíproca da maior diluição de soro capaz de prevenir a replicação viral. As médias dos títulos foram transformadas em títulos médios geométricos (GMT; THRUSFIELD, 1986) pela relação $\mathrm{GMT}=2^{\mathrm{a}}$, sendo “a” a média do $\log _{\mathrm{a}}$ do título de anticorpos. Para esse cálculo, somente foram considerados os títulos dos animais soropositivos (títulos $\geq 2$ ).

\section{Análise estatística}

A comparação entre as médias foi realizada através de análise de variância pelo teste de Tukey, com nível de significância de 5\%. Para a análise da correlação dose/resposta nos grupos de cobaias, os dados foram ajustados em linhas de tendência, utilizando-se modelos matemáticos lineares e nãolineares, escolhendo-se o modelo com maior coeficiente de determinação $\left(\mathrm{R}^{2}\right)$. $\mathrm{O}$ coeficiente de determinação $\mathrm{R}^{2}$ varia entre 0 e 1 , sendo que, quanto maior o valor, maior é a correlação estatística entre as variáveis.

\section{RESULTADOS E DISCUSSÃO}

O presente estudo foi delineado para estabelecer doses vacinais que induzissem em cobaias uma resposta sorológica neutralizante contra o BoHV1 e o BVDV equivalente à desenvolvida por bovinos imunizados com a dose recomendada para a espécie. $\mathrm{O}$ estabelecimento dessa correlação - e o estabelecimento de cobaios como modelo - permitiria o uso dessa espécie em testes preliminares de formulações vacinais contra esses vírus. A disponibilidade de um modelo laboratorial adequado pode viabilizar e facilitar várias etapas do desenvolvimento e avaliação de vacinas contra infecções víricas dos bovinos atualmente em curso no Brasil.

Os resultados dos testes sorológicos realizados com o soro dos bovinos e das cobaias colhidos 28 dias após a revacinação (dia 56) estão resumidos na tabela 1 . Nessa tabela, são apresentados os GMTs, o número de animais que reagiu sorologicamente em cada grupo/dose vacinal e os títulos de anticorpos neutralizantes individuais contra o BoHV-1 e BVDV.

Os grupos de cobaias imunizadas com doses eqüivalentes a $1 / 16(0,320 \mathrm{~mL})$ e $1 / 8(0,640 \mathrm{~mL})$ da dose bovina desenvolveram GMTs anti-BoHV-1 de 6,56 e 
7,46, respectivamente. Esses valores não diferiram estatisticamente entre si $(\mathrm{P}>0,05)$ e do GMT dos bovinos $(\mathrm{GMT}=8)$. Todos os bovinos imunizados, assim como as cobaias do grupo 5, reagiram à vacinação, enquanto uma cobaia do grupo 4 não apresentou resposta neutralizante detectável. A freqüência e a distribuição dos diferentes títulos foram semelhantes nesses três grupos. As cobaias do grupo 6 reagiram com títulos significativamente superiores (16 a 128), apresentando um GMT $(40,31)$ aproximadamente 5 vezes maior do que o dos bovinos $(\mathrm{P}<0,05)$. Em contraste, o número de reagentes e os GMTs dos grupos de cobaias imunizadas com doses menores (grupos 1, 2 e 3) foram inferiores $(\mathrm{P}<0,05)$, e vários animais de cada grupo não soroconverteram em níveis detectáveis. Os bovinos e as cobaias-controle permaneceram soronegativos durante o transcorrer do experimento (dados não demonstrados).

Apesar de nenhuma cobaia dos grupos 1 e 2 (doses de 5 e 20 microlitros, respectivamente) ter soroconvertido, verificou-se uma alta correlação $\left(\mathrm{R}^{2}=\right.$ $0,95)$ entre a dose vacinal e a magnitude da resposta neutralizante anti BoHV-1 (Figura 1A). Aúnica exceção foi o grupo 5, cujos animais receberam o dobro da dose do grupo 4, porém apresentaram um GMT estatisticamente semelhante ao desse grupo e, por isso, o grupo 5 manteve-se relativamente afastado da linha de tendência. Os títulos de anticorpos anti-BoHV-1 desenvolvidos pelas cobaias do grupo 6 demonstram que a relação dose-resposta vai além dos títulos equivalentes aos dos bovinos desenvolvidos pelos cobaias dos grupos 4 e 5 . Ou seja, a curva de correlação permanecia ascendente no ponto da maior concentração antigênica testada (Figura 1A). Portanto, a dose utilizada no grupo 6 não deveria ser adotada em testes vacinais, pois os valores dos GMTs superaram em muito os valores dos bovinos. Em resumo, os resultados obtidos indicam que cobaias imunizadas com doses correspondentes a 1/16 e 1/8 da dose bovina desenvolvem títulos neutralizantes de magnitude semelhante a dos bovinos. Doses similares a estas, portanto, seriam as recomendáveis para testes preliminares de imunogenicidade de vacinas inativadas anti-BoHV-1 nessa espécie. Esses resultados também sugerem que os títulos de magnitude baixa a moderada induzidos em bovinos por vacinas comerciais recentemente testadas (VOGEL et al., 2002; SILVA, 2006) podem ser decorrentes da baixa concentração antigênica nessas vacinas, a exemplo dos baixos títulos induzidos em cobaias imunizadas com doses inferiores.

A avaliação da resposta sorológica das cobaias frente ao BVDV não permitiu que se estabelecesse uma dose equivalente àquela de bovinos.
A maioria das cobaias dos grupos 1 a 4 permaneceu soronegativa ao BVDV, indicando que as doses de antígeno utilizadas nesses grupos foram insuficientes para induzir uma resposta sorológica neutralizante em nível detectável (Tabela 1). Apenas os grupos 5 $(0,640 \mathrm{~mL})$ e $6(1,6 \mathrm{~mL})$ reagiram satisfatoriamente (títulos entre <2 e 64, GMTs de 8 e 9, respectivamente), porém com títulos significativamente inferiores aos de bovinos (<2 a 128, GMT:38) $(\mathrm{P}<0,05)$. Além de baixos, os títulos individuais apresentaram uma ampla variação, a exemplo do grupo de bovinos (Tabela 1). Essa ampla variação de títulos neutralizantes induzidos por vacinas inativadas contra o BVDV também tem sido freqüentemente relatada em testes a campo (VOGEL et al., 2002; SILVA, 2006).

Os baixos títulos desenvolvidos pelas cobaias frente ao BVDV corroboram estudos prévios (KWEON et al., 1997; KEWON et al., 1999). Apesar de títulos entre 16 e 128 já terem sido demonstrados nessa espécie após imunização com a glicoproteína de envelope E2 do BVDV (KWEON et al., 1997), os mesmos foram detectados após um regime de três imunizações consecutivas com o antígeno acrescido ao adjuvante completo de Freund's, que é sabidamente mais imunogênico que o hidróxido de alumínio, utilizado no presente estudo. Nos grupos em que se administrou apenas o antígeno solúvel, acrescido ou não de complexo imunoestimulante (ISCOM), os títulos foram semelhantes aos verificados no presente estudo ( $<2$ e 32) (KWEON et al., 1997). No entanto, comparações entre os resultados obtidos no estudo atual e aqueles relatados por KWEON et al. (1997) devem ser interpretadas com cautela. Os autores avaliaram a imunogenicidade de um único antígeno, a glicoproteína E2, enquanto a vacina utilizada no presente trabalho é um imunógeno experimental contendo os antígenos totais do BVDV, ou seja, antigenicamente mais complexa.

Uma relação entre dose e resposta também foi estabelecida para o BVDV $\left(\mathrm{R}^{2}=0,71\right)$, porém com menor significância estatística que a correlação estabelecida para o BoHV-1 (Figura 1.B). A linha de tendência demonstra que os títulos atingiram um platô após uma determinada dose (entre grupos 5 e 6). Aparentemente, aumentos posteriores da dose não resultariam em títulos superiores. No entanto, os títulos desenvolvidos pelas cobaias foram inferiores aos desenvolvidos pelos bovinos. Portanto, estudos subseqüentes com doses maiores seriam necessários para se concluir se realmente os títulos não ultrapassariam o limite máximo aqui demonstrado, ou se doses superiores teriam potencial em induzir títulos equivalentes aos induzidos em bovinos frente ao BVDV, a exemplo do que foi demonstrado para o BoHV-1. 


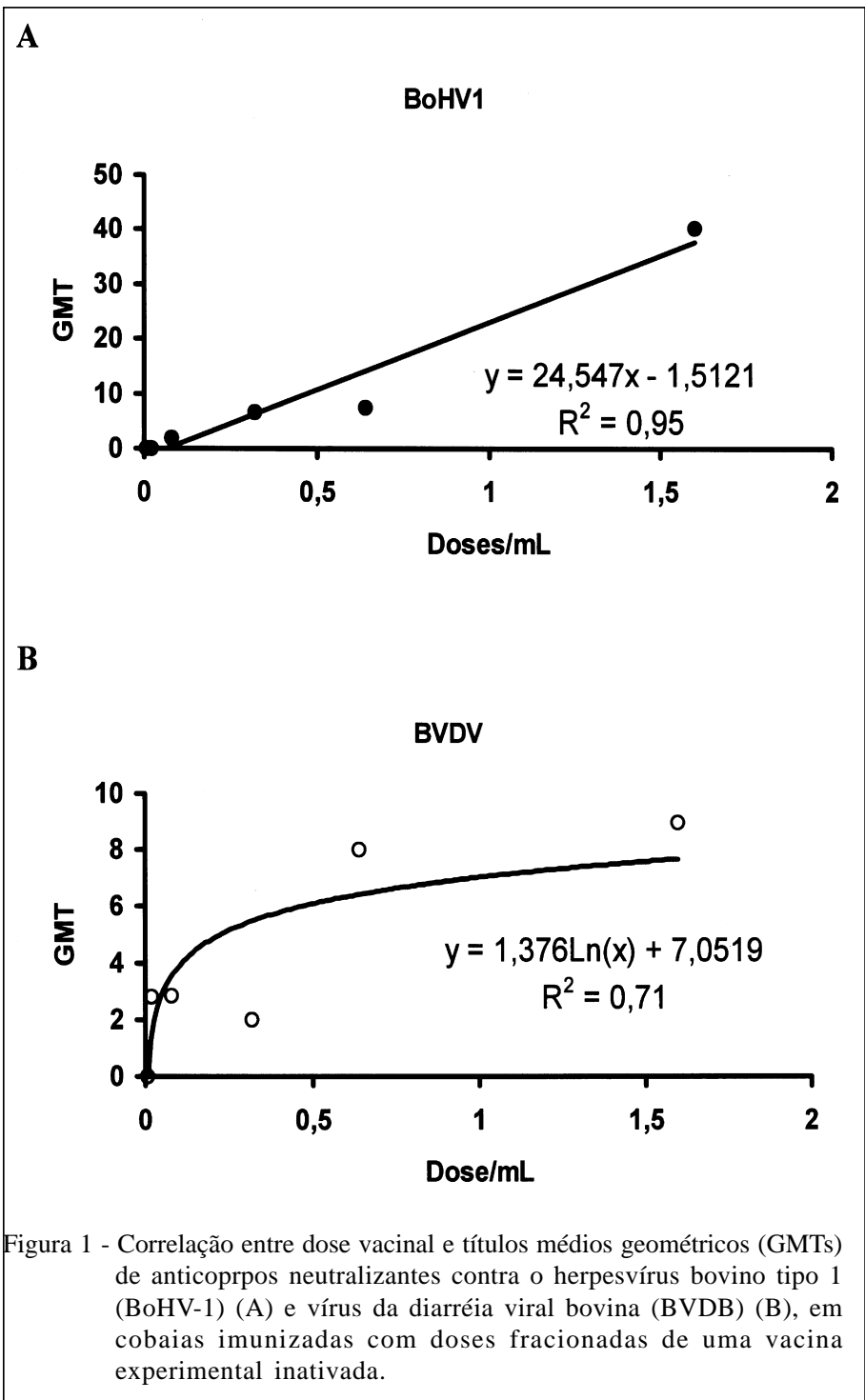

associados com a proteção da infecção pelo vírus da varicela zoster (VZV) (MATSUNGA et al., 1982). Essa espécie também tem sido freqüentemente utilizada em testes de vacinas recombinantes e de subunidade contra esses vírus (DA COSTA et al., 1997; BOURNE et al., 2003; HOSHINO et al., 2005). As cobaias também têm sido adotadas em testes de vacinas ou de anticorpos profiláticos contra vírus humanos, entre eles o vírus respiratório sincicial (RSV) e o metapneumovírus (hMPV; GRAHAM et al., 2000; WILLIAMS et al., 2005).

Esses dados, aliados aos obtidos no presente estudo, indicam que essa espécie se constitui em uma alternativa adequada para testes preliminares de vacinas víricas inativadas, como as que atualmente estão em desenvolvimento no Brasil.

\section{CONCLUSÕES}

Os resultados apresentados neste estudo permitem concluir que: i. cobaias podem ser utilizados em testes de imunogenicidade de formulações antigênicas inativadas do BoHV-1; ii. doses entre 1/16 e 1/8 da dose bovina induzem nesses animais títulos de anticorpos neutralizantes comparáveis aos produzidos pelos bovinos; iii. a resposta das cobaias a antígenos do BVDV foi inconsistente e de baixa magnitude na

Outros animais de laboratório têm sido utilizados em testes preliminares de vacinas víricas, porém apresentam restrições como: i. a ampla variação da resposta imunológica em diferentes linhagens de camundongos (GUPTA et al., 1999); ii. a citotoxicidade do soro dos coelhos para os cultivos celulares utilizados em testes de soroneutralização (FLORES, E.F. comunicação pessoal). Essas características e os resultados anteriores obtidos em estudos de imunidade e proteção vacinal para diferentes vírus subsidiaram a escolha de cobaias para a realização do presente estudo. Cobaias têm sido modelos adequados para se avaliar a proteção induzida por uma vacina atenuada contra o BoHV-2 (SMEE \& LENHART, 1994) e na investigação dos mecanismos imunológicos maioria das doses testadas; iv. doses superiores às testadas são provavelmente necessárias para a indução de títulos neutralizantes anti-BVDV equivalentes aos de bovinos.

\section{COMITÊ DE ÉTICA}

Os procedimentos com animais seguiram estritamente as normas do COBEA (Comitê Brasileiro de Experimentação Animal, lei n. 6.638 de 8 de maio de 1979), e foram aprovados pelo Comitê de Ética e Bem Estar Animal da UFSM (processo 23081.004287/2006-93, de 03 de abril de 2006).

\section{AGRADECIMENTOS}

Aos funcionários do Biotério Central da UFSM, na pessoa do Médico Veterinário Silvandro Noal, pelo auxílio inestimável na manutenção e nos cuidados com os animais.

Ciência Rural, v.37, n.4, jul-ago, 2007. 
DGD é bolsista de mestrado do CNPq; EFF (301666/2004-0) e RW (301339/2004-0) possuem bolsas PQ do CNPq. Ao Laboratório Vallée S.A., pelo suporte financeiro para a realização do mestrado (LFS).

\section{REFERÊNCIAS}

BAKER, J.C. Clinical manifestations of bovine viral diarrhea infection. Veterinary Clinics of North America, v.11, n.3, p.425-445, 1995

BOURNE, N. et al. Herpes simplex virus (HSV) type 2 glycoprotein D subunit vaccines and protection against genital HSV-1 or HSV-2 disease in guinea pigs. Journal of Infectious Diseases, v.187, n.4, p.542-549, 2003.

DA COSTA, X. et al. Construction and characterization of replication-defective herpes simplex virus 2 ICP8 mutant strain and its use in immunization studies in guinea pig model of genital disease. Virology, v.232, n.1, p.1-12, 1997.

FLORES, E.F. et al. A infecção pelo vírus da Diarréia Viral Bovina (BVDV) no Brasil - histórico, situação atual e perspectivas. Pesquisa Veterinária Brasileira, v.25, n.3, p.125-134, 2005.

GRAHAM, B.S. et al. Immune-mediated disease pathogenesis in respiratory syncytial virus infection. Immunopharmacology, v.48, n.3, p.237-246, 2000.

GUPTA, R.K. et al. Evaluation of guinea pig model to assess interference in the immunogenicity of different components of a combination vaccine comprising diphtheria, tetanus and acellular pertussis (DTaP) vaccine and Haemophilus influenzae type b capsular polysaccharide conjugate vaccine. Biologicals, v.27, n.2, p.167-176, 1999.

HOSHINO, Y. et al. Comparative efficacy and immunogenicity of replication-defective, recombinant glycoprotein, and DNA vaccines for herpes simplex virus 2 in mice and guinea pigs. Journal of Virology, v.79, n.1, p.410-418, 2005.

JONES, C. Alphaherpesvirus latency: its role in disease and survival of the virus in nature. Advances in Virus Research, v.51, p.81-133, 1998.

KWEON, C.H. et al. Expression of envelope protein (E2) of bovine viral diarrhea virus in insect cells. Journal of Veterinary Medical Science, v.59, n.5, p.415-419, 1997.
KWEON, C.H. et al. Bovine herpesvirus expressing envelope protein (E2) of bovine viral diarrhea virus as a vaccine candidate. Journal of Veterinary Medical Science, v.61, n.4, p.395401, 1999.

LOVATO, L.T. et al. Herpesvírus bovino tipo 1 (HBV-1): inquérito soro-epidemiológico no rebanho leiteiro do Estado do Rio Grande do Sul. Ciência Rural, v.25, n.3, p.425-430, 1995.

MATSUNGA, Y. et al. Experimental infection and immune response of guinea pigs with Varicella-Zoster virus. Infection and Immunity, v.37, n,2, p.407-412, 1982.

SILVA, L.F. Imunogenicidade de vacinas inativadas contra o herpesvírus bovino tipo 1 (BoHV-1) e vírus da diarréia viral bovina (BVDV) em bovinos e cobaios. 2006. 64f. Dissertação (Mestrado em Medicina Veterinária Preventiva) Programa de Pós-graduação em Medicina Veterinária, Universidade Federal de Santa Maria.

SMEE, D.; LENHARDT, J.A. Vaccination against bovine herpes mammilitis virus infections in guinea pigs. Intervirology, v.37, n.1, p.20-24, 1994.

THRUSFIELD, M. Veterinary epidemiology. London: Butterworths, 1986. 280p.

TIKOO, K.S. et al. Bovine hespesvirus 1 (BOHV-1): biology, pathogenesis and control. Advances in Virus Research, v.45, p.191-223, 1995.

VAN DRUNEN LITTLE-VAN DEN HURK, S. Rationale and perspectives on the success of vaccination against bovine herpesvirus-1. Veterinary Microbiology, v.31, n.113, p.34, 2005.

VAN OIRSCHOT, J.T. et al. Vaccination of cattle against bovine viral diarrhea. Veterinary Microbiology, v.64, n.2-3, p.169183, 1999.

VOGEL, F.S.F. et al. Magnitude, duração e especificidade da resposta sorológica em bovinos vacinados contra o vírus da diarréia viral bovina (BVDV). Ciência Rural, v.32, n.1, p.8389, 2002.

WILLIAMS, J.V. et al. The cotton rat (Sigmond hispidus) is a permissive small animal model of human metapneumovirus infection, pathogenesis, and protective immunity. Journal of Virology, v.79, n.17, p.10944-10951, 2005. 